\title{
Role of ALDH2 in Hepatic Disorders: Gene Polymorphism and Disease Pathogenesis
}

\author{
Qiaoling Wang ${ }^{+1,2}$, Binxia Chang ${ }^{+2}$ (), Xiaoyan $\mathrm{Li}^{3}$ (B) and Zhengsheng Zou*1,2(1) \\ ${ }^{1}$ Peking University, 302 Clinical Medical School, Beijing, China; 2Diagnosis and Treatment Center for Non-Infectious \\ Liver Diseases, Fifth Medical Center of Chinese PLA General Hospital, Beijing, China; ${ }^{3}$ Anhui Medical University,
} Hefei, Anhui, China

\begin{abstract}
Aldehyde dehydrogenase $2(\mathrm{ALDH} 2)$ is a key enzyme of alcohol metabolism and it is involved in the cellular mechanism of alcohol liver disease. ALDH2 gene mutations exist in about $8 \%$ of the world's population, with the incidence reaching $45 \%$ in East Asia. The mutations will result in impairment of enzyme activity and accumulation of acetaldehyde, facilitating the progression of other liver diseases, including non-alcoholic fatty liver diseases, viral hepatitis and hepatocellular carcinoma, through adduct formation and inflammatory responses. In this review, we seek to summarize recent research progress on the correlation between $A L D H 2$ gene polymorphism and multiple liver diseases, with an attempt to provide clues for better understanding of the disease mechanism and for strategy making.
\end{abstract}

Citation of this article: Wang Q, Chang B, Li X, Zou Z. Role of ALDH2 in hepatic disorders: Gene polymorphism and disease pathogenesis. J Clin Transl Hepatol 2021;000(000): 000-000. doi: 10.14218/JCTH.2020.00104.

Introduction of gene polymorphisms in aldehyde dehydrogenase 2

\section{Function of aldehyde dehydrogenase 2 in human be- ings}

The aldehyde dehydrogenases play a key role in the metabolism of toxic aldehydes. Some are produced in human

Keywords: Aldehyde dehydrogenase 2; Gene polymorphisms; Alcoholic liver disease; Non-alcoholic fatty liver disease; Viral hepatitis; Hepatocellular carcinoma. Abbreviations: 4-HNE, 4-hydroxy-2-nonenal; $A C H$, acetaldehyde; $A L D$, alcoholic liver disease; ALDH2, aldehyde dehydrogenase 2; ALT, alanine aminotransferase; AMPK, AMP-activated protein kinase; $\mathrm{CHB}$, chronic hepatitis B; CHC chronic hepatitis C. CYP2E1, Cytochrome P4502E1. GGT Y-glutamyl $\mathrm{B}$; CHC, Chronic hepatis ${ }^{\prime}$, CYP2E1, Cytochrome P452E1; GGT, Y-glutamy transpeptidase, Glu, glutamic acid; HBV, hepatitis B virus; $\mathrm{HCC}$, hepatocellu(y) lysine HDL-C, high-density lipoprotein cholesterol; HIF-1a, hypoxia-inducible factor-1 alpha; ISGs, interferon-stimulated genes; MDA, malondialdehyde; NAFLD, non-alcoholic fatty liver disease; NF-KB, nuclear factor-kappa B; PP2A, protein phosphatase $2 A$; ROS, reactive oxygen species; SNP, single nucleotide polymorphism; SREB-1, sterol regulatory element binding protein-1 pathway; STAT, signal transducer and activator of transcription; TG, triglyceride.

Received: 9 November 2020; Revised: 14 December 2020; Accepted: 18 December 2020

${ }^{\dagger}$ These authors contributed equally to this paper.

*Correspondence to: Zhengsheng Zou, The Center for Diagnosis and Treatment of Non-Infectious Liver Disease, The General Hospital of Chinese People's Liberation Army No. 5 Medical Science Center, No. 100 Xisihuan Middle Road, Beijing 100039, China. E-mail: zszou302@163.com bodies, such as 4-hydroxy-2-nonenal (4-HNE) and malondialdehyde (MDA), while others were obtained from the environment, like formaldehyde, acrolein, and ethyl. ${ }^{1,2}$ As a member of the ALDH superfamily, ALDH2 is the most sensitive isoform to irreversible inactivation and is also the most sensitive to inactivation by toxics, such as $4-\mathrm{HNE} .^{1}$ This enzyme could metabolize acetaldehyde $(\mathrm{ACH})$ to acetate irreversibly in a redox reaction (Fig. 1). ${ }^{3}$ Disturbances in the expression of $A L D H 2$ will dampen its metabolic capacity and result in accumulation of $\mathrm{ACH}$ consequently. Based on its electrophilic feature, $\mathrm{ACH}$ could bind with biomolecules such as proteins or DNA and destroy cell integrity, which contributes to the development of various human diseases, ${ }^{4}$ such as endocrine disorders, cardiovascular diseases, pulmonary diseases, oral cancers, gastrointestinal cancers, Fanconi anemia, and dermatitis. ${ }^{5-7}$

\section{ALDH2 gene and polymorphisms}

ALDH2 is a polypeptide consisting of 517 amino acids, principally expressed in the liver but also in other organs, such as heart, kidney, muscle, and brain. ${ }^{8}$ Its coding gene is located on chromosome 12 (12q24.2), which is 44 kilobases in length and comprises 13 exons. ${ }^{9}$ After translation, the expressed protein is transported to the mitochondrial matrix to participate in dehydrogenase, esterase and reductase reactions in liver and fat tissues particularly. Studies of the human genome have shown 19 kinds of functional $A L D H$ genes in total, with a wide range of expression and substrate specificities, among which the ALDH2 gene has the highest expression and exclusively harbors existence of genetic polymorphisms. ${ }^{1}$

As it encodes a key enzyme for alcohol metabolism, $A L D H 2$ also has an important functional single nucleotide polymorphism (SNP), the rs671-Glu504Lys variant, which has significantly reduced activity compared to the wild type. 10 The rs671 variant exists in $30-45 \%$ of East Asians (Chinese, Japanese, and Korean) and $8 \%$ of the world's population. 11,12 The incidence of this mutation in China is as high as $37-59 \% .13-16$ Nowadays, the rs671SNP locus at exon 12 is of special concern in worldwide research. According to sequencing detection, 17 a $\mathrm{G} \rightarrow \mathrm{A}$ point mutation is prone to occur at exon 12, causing the original glutamic acid (Glu) to be replaced by lysine (Lys), whose mutation is named ALDH2Glu504Lys (SNPrs671).

ALDH2rs671 SNPs are composed of three genotypes: GA, $A A$ and GG. GA is a heterozygous mutation, also named as $A L D H 2 * 1 / * 2$ (Glu/Lys). AA is a homozygous mutation, also known as ALDH2*2/*2 (Lys/Lys). GG is the normal allele, without mutation (Fig. 2). The majority of studies on these genotypes have confirmed that the GA genotype has 10$20 \%$ of the enzyme activity compared wild type, while the 
Wang Q. et al: ALDH2 gene polymorphism and liver disease

Ethanol

ADH1B

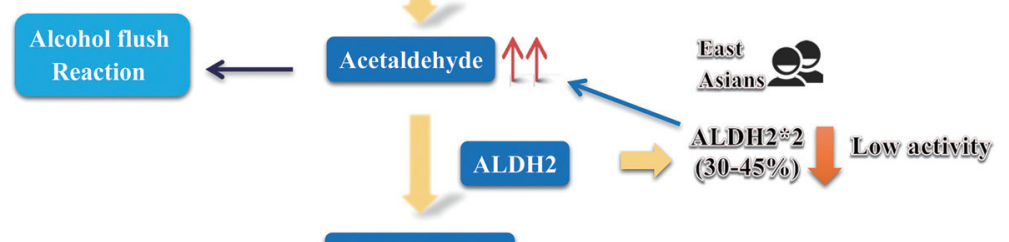

Acetate

Fig. 1. Alcohol metabolism and enzymes that strongly impact alcohol consumption. The $A L D H 2 * 2$ variant exists in $30-45 \%$ of East Asians (Chinese, Japanese, and Korean), which has low activity.

AA genotype loses more than $96 \%$ of the enzymatic activity. As a result, individuals with GA or AA mutations could show up to 6 or 19 times greater ACH concentrations, respectively, as compared with wild type after alcohol intake. ${ }^{18}$

\section{Distribution of ALDH2 alleles in different populations}

The genotype frequencies of the $A L D H 2$ gene polymorphisms vary among different races. The rare $A L D H 2 * 2$ allele has been observed in Caucasians, Africans and Southeast Asians but it is widely present in East Asians. ${ }^{19,20}$ There is a report of this mutation being found in about 560 million people of East Asian descent and reducing enzymatic activity by approximately $60 \%$ to $80 \%$ in $A L D H 2 * 1 / * 2$ heterozygotes. ${ }^{19}$ Among East Asians, the $A L D H 2$ allele frequencies are diverse among Japanese, Korean, and Chinese. In China, the $A L D H 2 * 2$ gene frequency in some Chinese aboriginal populations (e.g., Korean, Uighur, Zhuang and Olunchun) is lower compared to the Chinese Han population. In the Chinese Han population, the $A L D H 2 * 2$ allele frequency is $17 \%$ to $29 \%$, the proportion of individuals with $A L D H 2 * 1 / * 2$ heterozygotes is $36 \%$ to $44 \%$, and the proportion of individuals with $A L D H 2 * 2 / * 2$ homozygotes is $7 \%$ to $8 \% .21,22$

\section{Related liver diseases}

\section{Alcoholic liver disease}

Alcoholic liver disease (ALD) is a direct outcome of chronic ethanol consumption and is considered as an important health problem worldwide. ALD encompasses a broad spectrum of liver injuries, including steatosis, fibrosis, cirrhosis, and alcoholic hepatitis. ${ }^{23}$ The incidence of ALD has been increasing yearly because of the rapid boom in alcohol con- sumption in many developing countries over the past decade. ${ }^{24}$ The prevalence of ALD in China, the USA, Europe, and Japan is $4.5 \%, 6.2 \%, 6 \%$, and $1.56-2.34 \%$, respectively. ${ }^{24-27}$ There are about 260 million people occasionally, habitually and excessively drinking, and appropriately 2.5 million people die from ALD each year. ${ }^{28}$ Hence, ALD pathogenesis and therapy have always been the focus of national researchers.

The ALDH2 Glu504lys polymorphism is tied closely to occurrence and development of ALD in related individuals, 29 though its polymorphism does not contribute to alcohol dependence in the Turkish population. ${ }^{30}$ Regardless of homozygous AA or heterozygous GA status, both guarantee elevated $\mathrm{ACH}$ level after alcohol drinking. A single-center study from the Fifth Medical Centre of the General Hospital of the Chinese People's Liberation Army reported that only $2.3 \%$ of ALD patients have the $A L D H 2 * 2$ allele, compared with $14.5 \%$ of the proportion of healthy controls ( 281 and 535 controls; odds ratio [OR] of 0.13 and $95 \%$ confidence interval [CI] of $0.07-0.24){ }^{31}$ In Korea, Lee et al. ${ }^{32}$ found that the $A L D H 2 * 1$ allele is associated with a higher frequency of alcoholic cirrhosis $(p=0.001)$. Likewise, a meta-analysis of 12 studies found that people with the $A L D H 2 * 1$ allele are more likely to go on to develop alcoholic liver cirrhosis compared with those with either the $A L D H 2 * 1 / * 2$ or $A L D H 2 * 2 / * 2$ genotype. ${ }^{33}$ Based on the activity of the enzyme after gene mutation, $A L D H 2 * 2 / * 2$ should have produced a poor protective effect of ethanol; however, it brings some body information, such as facial flushing, reminding those with $A L D H 2 * 2 / * 2$ to be alert to alcohol intake and usually leading to little excessive ethanol consumption. ${ }^{34}$ On the contrary, without the gene reminder, those with $A L D H 2 * 1$ are not aware of consuming excessive alcohol.

The protection from the $A L D H 2$ Glu504lys polymorphism has also been verified by Liu's team, ${ }^{35}$ whose result demonstrated that individuals carrying this polymorphism are protected from alcohol drinking, with a 4-fold decrease in risk. Ma et al. ${ }^{36}$ and Li et al. ${ }^{16}$ also provided further evidence that
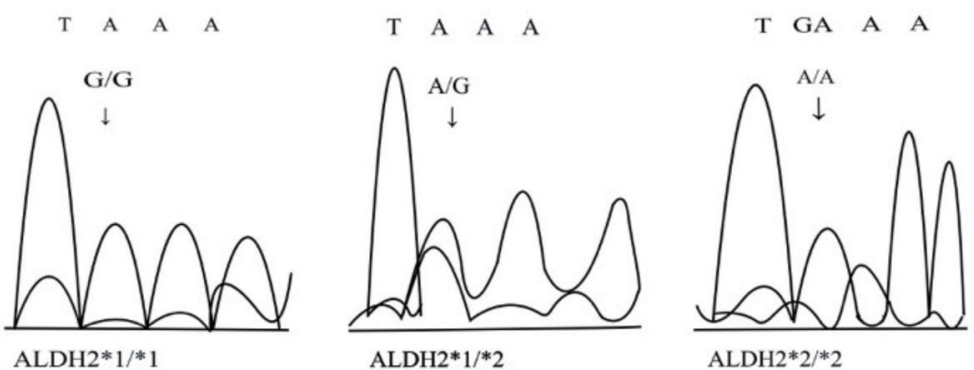

Fig. 2. Genotypes of ALDH2rs671. 
Wang Q. et al: ALDH2 gene polymorphism and liver disease

Table 1. Recent clinical studies on the relationship between the ALDH2 polymorphism and ALD

\begin{tabular}{|c|c|c|}
\hline Year & Conclusion & Reference \\
\hline 2001 & The $A L D H 2 * 2$ gene protects against the development of alcoholism. & 32 \\
\hline 2012 & $\begin{array}{l}\text { Strong protective effect of the ALDH2 504lys (*2) allele against alcoholism and alcohol-induced } \\
\text { medical diseases in Asians. }\end{array}$ & 16 \\
\hline 2015 & $\begin{array}{l}\text { The absence of the } A L D H 2 * 2 \text { allele in both alcoholics and controls suggests that this polymorphism } \\
\text { does not contribute to alcohol dependence in the Turkish population. }\end{array}$ & 30 \\
\hline 2015 & $\begin{array}{l}\text { ALDH2 plays a beneficial role in ameliorating chronic alcohol intake-induced hepatic steatosis and } \\
\text { inflammation, through regulation of autophagy. }\end{array}$ & 37 \\
\hline 2016 & $\begin{array}{l}\text { People with the } A L D H 2 * 1 \text { allele are more likely to go on to develop alcoholic liver cirrhosis compared } \\
\text { with those with the } A L D H 2 * 1 / * 2 \text { or } A L D H 2 * 2 / * 2 \text { genotype. }\end{array}$ & 33 \\
\hline 2016 & $\begin{array}{l}\text { Polymorphisms in } A L D H 2 \text { exerted significant indirect effects on hepatocellular carcinoma risk, } \\
\text { mediated through alcohol drinking. }\end{array}$ & 35 \\
\hline 2016 & $\begin{array}{l}\text { The ALDH2 Glu504Lys polymorphism and 'alcohol flush' are not harmless in the study's Asian } \\
\text { population. }\end{array}$ & 36 \\
\hline 2017 & $\begin{array}{l}\text { Individuals who carry at least one copy drink typically less and are protected against heavy alcohol } \\
\text { use and alcohol use disorders. }\end{array}$ & 34 \\
\hline 2018 & $\begin{array}{l}\text { Patients with the ALDH2 504lys variant were less associated with ALD compared to those with } A L D H 2 \\
\text { 504glu. }\end{array}$ & 31 \\
\hline 2019 & $\begin{array}{l}\text { ALDH2 deficiency is associated with elevated acetaldehyde and glucocorticoids post-alcohol } \\
\text { consumption, thereby inhibiting T cell activation and hepatitis. }\end{array}$ & 37 \\
\hline
\end{tabular}

Abbreviations: ALD, alcohol liver disease; ALDH2, aldehyde dehydrogenase 2; Glu, glutamic acid; Lys, lysine.

the mutation and "alcohol flush" are not harmless in this Asian population. In other words, the $A L D H 2$ gene mutation is a protective factor in the alcohol-drinking population in East Asia, while it is weaker in European and African populations. ${ }^{34}$ In fact, the Eastern culture encourages or challenges people to drink more alcohol in social activities, and sometimes people with flushing may not be able to escape or reject such alcoholism.

Aerobic glycolysis is involved in alcohol metabolism, which could be inhibited by a known factor: corticosterone. As is shown in the animal experiment of Gao's team, ${ }^{37}$ a higher level of serum corticosterone is detected in ethanol-fed Aldh2(-/-) mice, compared to the wild type mice. Gao's team ${ }^{37}$ also found that acute alcohol drinking in humans was related to elevated plasma glucocorticoid levels in human subjects, with higher levels in those with inactive ALDH2 than active ALDH2. To conclude, the progress of aerobic glycolysis is impaired by ethanol, especially in those with $A L D H 2 * 2$. Meanwhile, they succeeded in restored concanavalin A-mediated hepatitis via blockade of corticosterone. Therefore, aerobic glycolysis-related signaling pathways may be a key factor. Interestingly, the authors found that glucose metabolism in T cells could be disrupted by $\mathrm{ACH}$ through inhibition of the aerobic glycolysis-related signal pathways. In addition, weakened autophagy is involved and compromised lysosomal activity will lead to abnormal stacking of ethanol or acetaldehyde by-product including protein or DNA adducts. Guo et al. ${ }^{38}$ reported that observations both in vivo and in vitro are in favor of a beneficial role of ALDH2 in alcohol intake-facilitated fatty liver and inflammation through autophagy regulation (Table 116,30-37).

The traditional hypothesized pathway is through oxidative stress. ALDH2 dramatically attenuates hepatic oxidative stress induced by chronic alcohol intake and favors a role of oxidative stress in ethanol- and ALDH2-elicited hepatic responses, by restoring autophagy and reopening autophagy flux. Additional ethanol consumption will increase the production of NADH/NAD+, and reactive oxygen species (ROS) in the mitochondrial electron transport chain. Then, ROS is able to activate nuclear factor-kappa B (NF-KB) and its downstream proinflammatory signal, and correspondingly aggravate inflammation and hepatocyte damage.39-41 Moreover, Zhong et al..$^{42}$ selected mitochondrial ALDH2 as a promising therapeutic target for ALD. They said that it accelerates aldehyde clearance and reverses hepatic steatosis and apoptosis in mice. Therefore, artificial modulation of $A L D H 2$ expression may be a potential therapeutic intervention for alcoholism and ALD in the future. 43,44

As mentioned above, variants in ALDH2 decrease the rate of $\mathrm{ACH}$ conversion to acetate because it blocks its ability to remove $\mathrm{ACH}$ and results in a strong aversive reaction. Therefore, if we can find a medium to intervene this mechanism and develop a blocker, we will alleviate this effect. It is also suggested that physicians should pay attention to explore the potential immunosuppressive therapy in alcoholics.

\section{Non-alcoholic fatty liver disease}

It has become more and more accepted that non-alcoholic fatty liver disease (NAFLD) stands for not just a single type of liver disease but the hepatic manifestation of complicated metabolic dysfunctions. NAFLD covers a wide range of liver pathologies, including steatosis, steatohepatitis, fibrosis/cirrhosis and liver failure. ${ }^{14,45}$ Nowadays, NAFLD has become the leading cause of chronic liver diseases on earth and its global prevalence is appropriately $25 \% .46-49$ Prevalence rates of NAFLD were estimated to be $22.4 \%, 24.13 \%, 23.71 \%$, $25 \%, 31 \%$ and $32 \%$ in China, the USA, Europe, Japan, the Middle East, and South America, respectively. ${ }^{14,24,50,51}$ In the USA, NAFLD is estimated to be the most common cause of chronic liver disease, affecting between 80 and 100 million individuals, among whom nearly $25 \%$ progress to nonalcoholic steatohepatitis. ${ }^{14} \mathrm{~A}$ recent report of data from the National Health and Nutrition Examination Survey ranging from 1988 to 2010 indicated that modest alcohol consumption (7-21 g/day) is associated with decreased mortality among patients with NAFLD. 52 In contrast to the studies of 58,927 patients with NAFLD in Korea, even moderate drink- 
ers (10-29.9 g/day) exhibited an increased tendency to progress to fibrosis compared with non-drinkers. ${ }^{53}$ Whether consuming moderate alcohol could be a lifestyle intervention in the treatment requires further investigation.

In China and East Asia, genome-wide association studies found that ALDH2 rs671 is a susceptible gene locus for obesity and significantly associated with increased body mass index and visceral fat deposition. ${ }^{10,11} \mathrm{~A}$ control study reported that a significant accumulation of the 4-HNE protein adduct and a significant up-regulation of $A L D H 2$ protein expression are found in the two groups of non-alcoholic steatohepatitis patients, suggesting that $A L D H 2$ plays a role in combating non-alcoholic steatohepatitis oxidative stress. We have reason to speculate that $A L D H 2$ gene mutation will reduce the oxidative stress protection response of liver recovery in non-alcoholic steatohepatitis patients. On the contrary, Alda-1, as an activator of ALDH2, suppresses PINK1/PARKIN-mediated mitophagy and its usage in apoE-mice has led to improvement in the degree of arteriosclerosis and hepatic steatosis, indicating that activation of ALDH2 can improve NAFLD on the condition of mitochondrial injury caused by vinyl chloride. ${ }^{54}$ Alda-1 protects against liver damage under these conditions via increasing clearance of aldehydes and preserving mitochondrial respiratory function.

In the field of biomedicine, researchers have found that inhibition of $A L D H 2$ enhances the $\mathrm{ACH}$-mediated hepatocyte sterol regulatory element binding protein-1 (SREB-1) pathway activity and promotes triglyceride (TG) deposition in the liver. A cohort study ${ }^{55}$ conducted by Japanese researchers followed 341 patients who never or seldom drank or drank less for 4-6 years and found that the incidence of NAFLD is higher in carriers of the mutant gene $A L D H 2 * 2$ than in non-carriers. Carriers of $A L D H 2 * 2$ with elevated y-glutamyl transpeptidase (GGT) levels (>25.5 IU/L) have a significantly increased risk of NAFLD. A recent Japanese study investigated the association of ALDH2rs671 genotype with liver disease in 1,768 alcohol-dependent Japanese men. They found that the ineffective ALDH2 Glu/Lys genotype increases the ratio or regression coefficient of age- and alcohol-adjusted fatty liver, ketonuria and serum high-density lipoprotein cholesterol (HDL-C) level, and reduces liver cirrhosis and serum TG level. Through logistic regression analysis, Chinese scientists also found that the GGT level in carriers of the GA/AA type is significantly higher than that of the GG type, suggesting that carriers of the GA/AA type are more prone to suffer liver cell damage and more severe fatty changes than carriers of the GG type. Nevertheless, another animal study suggested that ALDH2-deficient individuals may be resistant to steatosis and blood alanine aminotransferase (ALT) elevation but be more prone to liver inflammation and fibrosis following alcohol consumption. ${ }^{15}$ Furthermore, a human experiment showed that the prevalence of elevated ALT level increases with the accumulation of components of metabolic syndrome and that the correlation between active ALDH2 and elevated ALT level is sensitive. ${ }^{56}$ Their logistic regression analysis also revealed that body mass index, TG level, and ALDH2 genotype are associated with ALT elevation. This result coincides with the findings of the genome-wide association studies.

To conclude, the relationship between ALDH2 and the NAFLD disease spectrum has begun to enter the laboratory stage but it needs a large number of research studies to clarify the connection.

\section{Viral hepatitis}

Although the global incidence of viral hepatitis, hepatitis $B$ virus (HBV) infection mainly, is going down, it continues to play an important role in developing countries. ${ }^{57}$ There are approximately 257 million people with chronic HBV infection globally, including $68 \%$ in Africa and the Western Pacific, according to a World Health Organization report. 58 In China, chronic hepatitis B (CHB) and chronic hepatitis $\mathrm{C}(\mathrm{CHC})$ affect 90 million and 10 million people, respectively. In developed countries such as the USA, Japan, and the European Union, the prevalence of HBV is much lower $(0.71-1.17 \%)$, but the prevalence of hepatitis $C$ virus (HCV) $(1.10-1.56 \%)$ is higher than in China (HBV: $6.52 \%$; HCV: $0.72 \%$ ). In 2016 , the Global Health Sector Strategy on viral hepatitis called for elimination of viral hepatitis as a major public health threat by 2030.59 However, unlike other liver diseases, the relationship between viral hepatitis and $A L D H 2$ remains unclear.

$\mathrm{HCV}$ infection is an important cause of chronic liver disease, with nearly 71 million chronically infected people worldwide. ${ }^{57} \mathrm{HCV}$ and alcohol intake are both risk factors for accelerated fibrosis progression, ${ }^{60}$ and alcohol use in the setting of HCV infection is correlated with increased rates of fibrosis progression. ${ }^{61}$ Based on previous studies, 62,63 the correlation between $A L D H 2$ and HCV could be explained by the two following aspects: enhanced virus replication and immunity suppression.

For one thing, the metabolite $\mathrm{ACH}$ could help to activate the expression of miR-122 and miR-34a, both able to stimulate HCV replication. ${ }^{64}$ Correspondingly, a large number of virus products brought about by strong virus replication will promote hepatocellular apoptosis. Apoptosis has a secondary amplification effect on the viral lethality in the liver, which not only delays virus clearance but also aggravates liver cell damage. And, then, Kupffer cells and hepatic stellate cells (HSC) are driven by interleukins to aggregate and participate in the phagocytosis and clearance of apoptotic bodies. 62 This process will accelerate the inflammatory responses and fibrogenesis in the liver. Meanwhile, $\mathrm{ACH}$ could increase the activity of protein phosphatase $2 \mathrm{~A}$ (PP2A). ${ }^{65}$ PP2A could reduce methylation of signal transducer and activator of transcription (STAT)-1 and formation of the protein inhibitor of the activated STAT-1 PIAS1-STAT-1 complex. ${ }^{64}$ Ultimately, the damage will enhance destruction of STAT- 1 caused by HCV, thereby increasing the apoptosis (Fig. 3).

For another, some scientists have claimed that impairment of immunity is a probable cause. Ethanol exposure enhances the inhibitory effect of HCV on innate immunity, thereby activating the spread of the virus in the liver and eventually leading to impaired adaptive immunity. ${ }^{63}$ The expression of interferon-stimulated genes (commonly referred to as ISGs) compromises over 300 antiviral molecules that synergistically exert innate immunity and are under control of the catalysis of retinol and retinoic acid biogenesis. 65 Interestingly, the toxicity of these two substances can be suppressed by ALDH metabolism. It means that inhibition of ALDH will hinder the body's antiviral ability through the ISGs pathway. Therefore, one of the molecular mechanisms for the synergism between HCV and alcohol abuse in liver disease progression is hepatocyte metabolism involving ethanol-retinol metabolic competition. 66

In addition, activated $T$ cells can be combined with other immune cells to form a positive feedback effect, being aroused by various cellular factors in turn, in a bid to stir up inflammation and inhibiting further liver damage. Gao et al. ${ }^{37}$ discovered the phenomena that alcohol-fed Aldh2-/mice were less sensitive to concanavalin A-induced $T$ cell hepatitis than wild type mice. Their further study suggested that $\mathrm{ACH}$ directly restrained cytokine production in T cells by means of the inhibition of aerobic glycolysis or stimulation of corticosterone release, leading to the occurrence of suppressed T cell hepatitis in ethanol-fed Aldh2-/- mice. What is more, there is a certain correlation between the HBV epi- 


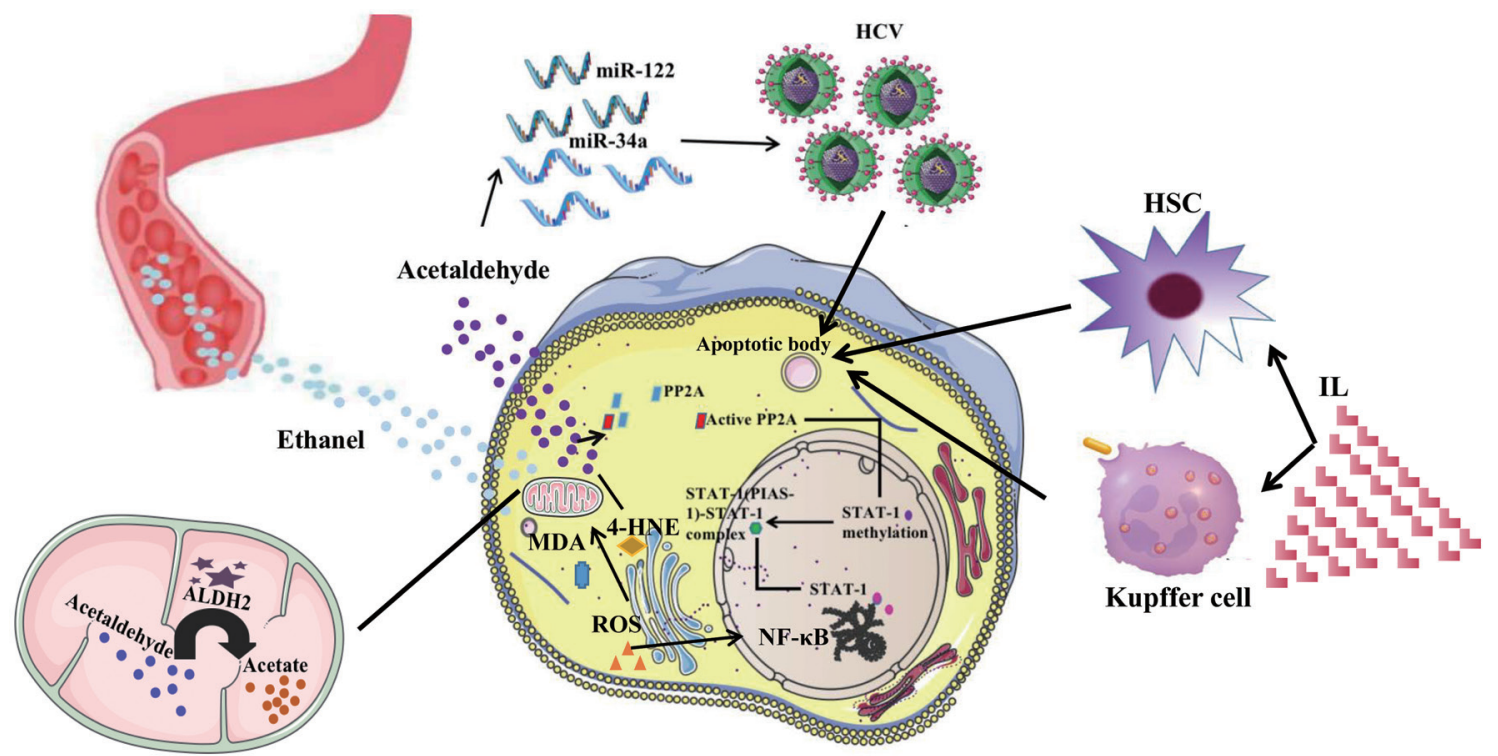

Fig. 3. Effect of ALDH2 in HCV infection and toxic aldehydes. Ethanol is converted to acetaldehyde by the cytosolic enzyme ADH. Then acetaldehyde is converted to acetate by $\mathrm{ALDH} 2$. ACH could help to activate the expression of miR-122 and miR-34a, both of which are able to stimulate hepatitis $\mathrm{C}$ virus replication, leading to apoptosis. Kupffer cells and hepatic stellate cells (HSC) are driven by interleukins and aggregate to participate in the phagocytosis and clearance of apoptotic bodies. ACH also increases the activity of PP2A. PP2A could reduce methylation of signal transducer and activator of transcription (STAT)-1 and formation of the protein inhibitor of activated STAT-1 PIAS-1-STAT-1 complex. 4-hydroxy-2-nonenal (4-HNE) and malondialdehyde (MDA) are toxic aldehydes in human bodies, which are produced by reactive oxygen species (ROS). Meanwhile, ROS could activate nuclear factor-kappa B (NF-KB) and its downstream targets.

demic area and the distribution of $A L D H 2$ gene-defect areas in East Asia. ${ }^{67}$ Almost all patients with ALDH2 mutation genotypes are linked with HBV infection. ${ }^{68}$ Among patients with chronic HBV, homozygous carriers of the $A L D H 2 * 2$ mutant gene have a significantly increased risk of developing liver cirrhosis.

Generally speaking, there is an optimistic link between $A L D H 2$ and $\mathrm{HCV}$, and alcohol is undoubtedly a factor that aggravates the development of HCV disease and may also be a break-through point in the design of research experiments.

\section{Hepatocellular carcinoma}

Hepatocellular carcinoma ( $\mathrm{HCC}$ ) is the sixth most common cancer and the third leading cause of cancer mortality in the world. ${ }^{69}$ In China, HCC has emerged as one of the top three malignant tumors, according to rankings by prevalence and mortality. ${ }^{70,71}$ The prevalence rates of HCC were reportedly $0.03 \%, 0.01 \%,<0.01 \%$, and $<0.01 \%$ among the general population in China, the USA, Europe, and Japan, respectively. ${ }^{25}$ Meanwhile, HCC cases are increasing rapidly in China, 69 which accounts for approximately $90 \%$ of all cases of primary liver cancer. ${ }^{72}$ Therefore, scientists have been endeavoring to explore the relationship between ALDH2 gene mutation and HCC (Table 235,73-79).

Generally, HBV infection and ALD are two major liver diseases with HCC developing tendency. ${ }^{60}$ Hou et al. ${ }^{73}$ inhibited aggressive behavior in vitro and in mice by forcing the expression of ALDH2 in HCC cells. Recently, Liu et al. ${ }^{35}$ explored the association between $A L D H 2$ polymorphisms and the risk of HCC among CHB patients, and their result showed that ALDH2 polymorphisms has nothing to do with $\mathrm{HCC}$ but does protect against developing HCC through habitual alcohol drinking, which was reported in another research study as well. ${ }^{74}$ Similarly, based on an analysis of 4,155 hepatitis B surface antigen seropositive participants, there is a distinct relationship between an increased risk of $\mathrm{HCC}$ in the HBV-positive cirrhosis population and ALDH2 gene polymorphisms. ${ }^{75}$ Recently, a study involving both mice and human patients showed that ALDH2 gene deficiency correlates well with a higher risk for advancement of alcohol related-fibrosis to HCC. 76

A meta-analysis conducted by Chen et al. ${ }^{77}$ found that the ALDH2 rs671 polymorphism is not associated with HCC susceptibility in East Asians, and this is similar to the conclusion from Liu et al. ${ }^{35}$ Interestingly, Huang et al. ${ }^{78}$ found that the $A L D H 2$ polymorphisms had a certain impact on resolution of HCC in patients. The result showed that HCC patients with a defective allele of $A L D H 2$ have a promising postoperative outcome, after Kaplan-Meier analysis and univariate followed by multivariate Cox proportional hazard analysis indicated that the GG genotype is an independent clinical predictor for shorter time-to-distant metastasis (adjusted $p=0.019$ ) and shorter overall survival (adjusted $p=0.001$ ). Although the $A L D H 2 * 2$ mutation itself does not lead to liver cancer directly, it will reduce ALDH2 protein levels and liver enzyme, which eventually is related to the accumulation of $\mathrm{ACH}$ in the blood and carcinogenic mutations. Likely, the results of animal experiments show that the mouse $A L D H 2$ (E487K) mutation significantly promotes the occurrence and development of mouse liver cancer.79

Unfortunately, despite a series of strong evidence supporting ethanol as an environmental risk factor for HCC, the exact pathways by which alcohol causes HCC are still under exploration. $\mathrm{ACH}$ has been shown to affect DNA replication and repair mechanisms. After chronic alcohol exposure, Aldh2-deficient animals produce a large amount of harmful oxidized mitochondrial DNA via extracellular vesicles, which can be delivered into neighbor HCC cells and subsequently activate multiple oncogenic pathways, to promote HCC development (Fig. 4). ${ }^{76}$ What is more, consuming a large amount of ethanol induces microsomal ethanol metabolism by cytochrome P4502E1 (known as CYP2E1) and leads to additional production of acetaldehyde, as well as an in- 
Wang Q. et al: ALDH2 gene polymorphism and liver disease

Table 2. Recent clinical studies on the relationship between the ALDH2 polymorphism and HCC

\begin{tabular}{|c|c|c|c|}
\hline Author & Year & Conclusion & Reference \\
\hline Liu et al. & 2016 & $\begin{array}{l}\text { Polymorphisms in } A L D H 2 \text { had significant indirect effects on HCC risk, mediated } \\
\text { through alcohol drinking. }\end{array}$ & 35 \\
\hline Hou et al. & 2017 & $\begin{array}{l}\text { Inhibiting aggressive behavior both in vitro and in mice by forcing the expression of } \\
A L D H 2 \text { in HCC cells. }\end{array}$ & 73 \\
\hline Ye et al. & 2018 & $\begin{array}{l}\text { The mutant genotypes of } A L D H 2 \text { may be protective factors for HCC susceptibility in } \\
\text { Guangxi Province, China. }\end{array}$ & 74 \\
\hline Chien et al. & 2016 & $\begin{array}{l}\text { GG genotype of } A L D H 2 \text { rs } 671 \text { was an HCC risk predictor in cirrhotic chronic hepatitis B } \\
\text { patients. }\end{array}$ & 75 \\
\hline Seo et al. & 2019 & $\begin{array}{l}\text { ALDH2 deficiency is associated with an increased risk of alcohol-related HCC } \\
\text { development from fibrosis in human patients and in mice. }\end{array}$ & 76 \\
\hline Chen et al. & 2020 & ALDH2 rs671 polymorphisms are not associated with HCC susceptibility in East Asians. & 77 \\
\hline Huang et al. & 2019 & $\begin{array}{l}\text { HCC patients carrying a defective allele of } A L D H 2 \text { had a favorable postoperative } \\
\text { outcome. }\end{array}$ & 78 \\
\hline Jin et al. & 2015 & $\begin{array}{l}\text { ALDH } 2 \text { plays a role of tumor suppressor by maintaining the stability of genome in the } \\
\text { liver, and the common human ALDH } 2 \text { variant would become an important risk factor } \\
\text { for hepatocarcinogenesis. }\end{array}$ & 79 \\
\hline
\end{tabular}

Abbreviations: ALDH2, aldehyde dehydrogenase 2; CYP2E1, cytochrome P4502E1; HCC, hepatocellular carcinoma.

crease in free radicals that can result in cell death, DNA damage, and even production of other carcinogenic substances.80,81 Other hypothesized pathways have included the transactivator protein $\mathrm{X}$ that is encoded by HBV and remolded to the extracellular matrix through hypoxia-inducible factor-1a (HIF-1a) target genes and the lysyl oxidase (HIF-1a/LOX) pathway to promote HCC metastasis. ${ }^{82}$ The ALDH2-acetaldehyde-redox-AMP-activated protein kinase (AMPK) axis participates in the regulation of $\mathrm{ACH}$ levels, which is activated by ALDH2. Therefore, identifying ALDH2 expression levels in HCC might be a useful biomarker for determining prognosis and developing targeted therapies that are urgently needed to treat patients with HCC.

In addition, human liver cancer tissue test results show that $A L D H 2 * 2$ protein is extremely unstable in human liver, and the low expression of $A L D H 2$ protein has a certain correlation with the formation of liver cancer. The Journal of Hepatology also reports that a deficiency in the $A L D H 2$ gene expression is associated with an increased risk of HCC in patients with hepatitis B cirrhosis who overtake alcohol. Both in vivo and in vitro studies have found that liver cells from $A L D H 2$-deficient mice can produce a large amount of harmful oxidized mitochondrial DNA, ${ }^{32}$ which is transferred to adjacent liver cells through extracellular vesicles and can activate multiple carcinogenic pathways involving $\mathrm{ACH}$ (JNK , STAT3, BCL-2, and TAZ) to promote the occurrence of alcohol-related HCC. ${ }^{73}$ ALDH2 could also affect metabolism by regulating the ALDH2-acetaldehyde-redox-AMPK

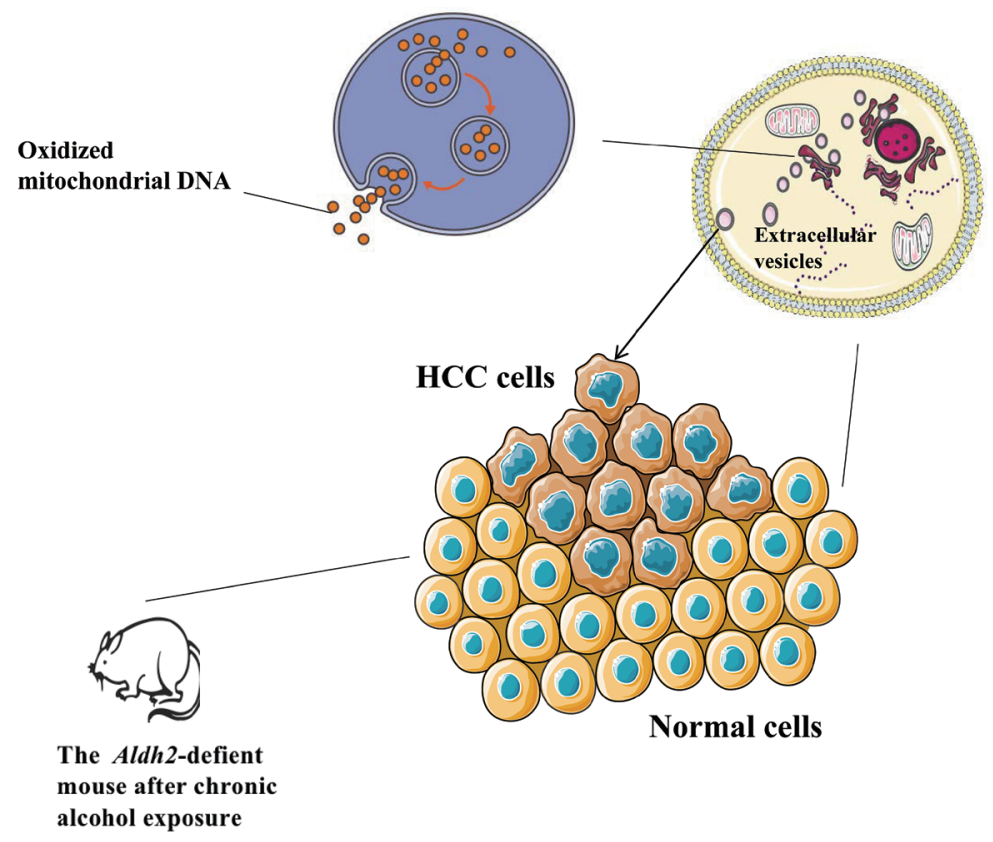

Fig. 4. Effect of ALDH2 on HCC cells. After chronic alcohol exposure, the Aldh2-deficient mice produce a large amount of harmful oxidized mitochondrial DNA which are delivered into neighboring hepatocellular carcinoma (HCC) cells via extracellular vesicles. 
axis, 83 because AMPK can direct lipid metabolism to regulate tumor cell growth and survival. Actually, in proteomics studies, among the proteins related to metabolism and liver function, ALDH2 does not have the highest expression level of enzymes, compared to ALDH1, ALDH4 and ALDH9A, according to the characteristics of the metabolic subgroup; ${ }^{84}$ however, we cannot look down upon the role of $A L D H 2$ in HCC. Zahid et al. ${ }^{85}$ reported transcriptional suppression of alcohol metabolism regulators, and demonstrated that $A L D H 2$, downstream of the mTOR signal, is partly responsible for triggering oncogenic transformation of hepatocytes, resulting in disease onset and progression in HCC in silico.

In summary, $A L D H 2$ is a potential risk factor for HCC. However, the clinical correlation between ALDH2 gene polymorphism and the occurrence and development of liver cancer remains to be further studied.

\section{Conclusions}

ALDH2 is a key enzyme in alcohol metabolism, and its genetic mutations are mainly clustered in East Asia. The genetic mutations of $A L D H 2$ will depress ALDH2 enzyme activity and provoke accumulation of $\mathrm{ACH}$, which will lead to the destruction of liver cells. Importantly, $A L D H 2$ gene mutation and the potential impact of $\mathrm{ACH}$ on $\mathrm{T}$ cell response may become one of the factors affecting the progression of liver disease and outcomes of global liver disease. In conclusion, understanding the impact of disease progression related to the $A L D H 2$ gene may be helpful for the improvement of future liver disease prevention strategies.

\section{Funding}

This paper was supported by the National Natural Science Foundation of China (NSFC), Grant numbers 81600467 and 81670527.

\section{Conflict of interest}

The authors have no conflict of interests related to this publication.

\section{Author contributions}

Review design (BC), drafting of the manuscript and figure design $(\mathrm{QW})$, language and grammar perfection $(\mathrm{XL})$, revising the manuscript for important intellectual content (QW, $\mathrm{BC}, \mathrm{ZZ})$, critical revision (ZZ).

\section{References}

[1] Yoval-Sánchez B, Rodríguez-Zavala JS. Differences in susceptibility to inactivation of human aldehyde dehydrogenases by lipid peroxidation byproducts. Chem Res Toxicol 2012;25:722-729. doi:10.1021/t×2005184.

[2] Jackson B, Brocker C, Thompson DC, Black W, Vasiliou K, Nebert DW, et al. Update on the aldehyde dehydrogenase gene (ALDH) superfamily. Hum Genomics 2011;5:283-303. doi:10.1186/1479-7364-5-4-283.

[3] Vasiliou V, Pappa A, Petersen DR. Role of aldehyde dehydrogenases in endogenous and xenobiotic metabolism. Chem Biol Interact 2000;129:1-19. dogenous and xenobiotic metabolism.
doi:10.1016/s0009-2797(00)00211-8.

[4] Fritz KS, Petersen DR. An overview of the chemistry and biology of reactive aldehydes. Free Radic Biol Med 2013;59:85-91. doi:10.1016/j.freeradbiomed.2012.06.025.

[5] Zambelli VO, Gross ER, Chen CH, Gutierrez VP, Cury Y, Mochly-Rosen D. Aldehyde dehydrogenase-2 regulates nociception in rodent models of acute inflammatory pain. Sci Transl Med 2014;6:251ra118. doi:10.1126/ scitranslmed.3009539.
[6] Tawa EA, Hall SD, Lohoff FW. Overview of the genetics of alcohol use disorder. Alcohol Alcohol 2016;51:507-514. doi:10.1093/alcalc/agw046.

[7] Prabavathy D, Swarnalatha Y, Ramadoss N. Lung cancer stem cells-origin, characteristics and therapy. Stem Cell Investig 2018;5:6. doi:10.21037/ sci.2018.02.01.

[8] Tsou PS, Page NA, Lee SG, Fung SM, Keung WM, Fung HL. Differential metabolism of organic nitrates by aldehyde dehydrogenase $1 \mathrm{a} 1$ and 2 : substrate selectivity, enzyme inactivation, and active cysteine sites. AAPS substrate selectivity, enzyme inactivation, and active cy

[9] Wenzel P, Hink U, Oelze M, Schuppan S, Schaeuble K, Schildknecht S, et al. Role of reduced lipoic acid in the redox regulation of mitochondrial aldehyde dehydrogenase (ALDH-2) activity. Implications for mitochondrial oxidative stress and nitrate tolerance. J Biol Chem 2007;282:792-799. doi:10.1074/jbc.M606477200.

[10] Zhu Y, Zhang D, Zhou D, Li Z, Li Z, Fang L, et al. Susceptibility loci for metabolic syndrome and metabolic components identified in Han Chinese: a multi-stage genome-wide association study. J Cell Mol Med 2017;21:11061116. doi:10.1111/jcmm.13042.

[11] Chen CH, Ferreira JC, Gross ER, Mochly-Rosen D. Targeting aldehyde dehydrogenase 2: new therapeutic opportunities. Physiol Rev 2014;94:1-34. doi:10.1152/physrev.00017.2013.

[12] Yokoyama A, Taniki N, Hara S, Haysashi E, Nakamoto N, Mizukami T, et al. Slow-metabolizing ADH1B and inactive heterozygous ALDH2 increase vulnerability to fatty liver in Japanese men with alcohol dependence. J Gastroenterol 2018;53:660-669. doi:10.1007/s00535-017-1402-6.

[13] Fan JG, Kim SU, Wong VW. New trends on obesity and NAFLD in Asia. J Hepatol 2017;67:862-873. doi:10.1016/j.jhep.2017.06.003.

[14] Perumpail B], Khan MA, Yoo ER, Cholankeril G, Kim D, Ahmed A. Clinical epidemiology and disease burden of nonalcoholic fatty liver disease. World J Gastroenterol 2017;23:8263-8276. doi:10.3748/wjg.v23.i47.8263.

[15] Kwon HJ, Won YS, Park O, Chang B, Duryee MJ, Thiele GE, et al. Aldehyde dehydrogenase 2 deficiency ameliorates alcoholic fatty liver but worsens liver inflammation and fibrosis in mice. Hepatology 2014;60:146-157. doi:10.1002/hep.27036

[16] Li D, Zhao H, Gelernter J. Strong protective effect of the aldehyde dehydrogenase gene (ALDH2) 504lys (*2) allele against alcoholism and alcohol-induced medical diseases in Asians. Hum Genet 2012;131:725-737. hol-induced medical diseases in Asia

[17] Li R, Zhao Z, Sun M, Luo J, Xiao Y. ALDH2 gene polymorphism in different types of cancers and its clinical significance. Life Sci 2016;147:59-66. doi:10.1016/j.Ifs.2016.01.028.

[18] Ye Y, Chen F, Lu X, Wu H, Lu Q, Shi L, et al. Correlation of genetic polymorphism, alcoholic beverage type and ethanol metabolism. Fa Yi Xue Za Zhi 2018;34:142-146. Chinese doi:10.3969/j.issn.1004-5619.2018.02 007 .

[19] Gross ER, Zambelli VO, Small BA, Ferreira JC, Chen CH, Mochly-Rosen D. A personalized medicine approach for Asian Americans with the aldehyde de-
hydrogenase $2 * 2$ variant. Annu Rev Pharmacol Toxicol 2015;55:107-127. doi:10.1146/annurev-pharmtox-010814-124915.

[20] Wang W, Wang C, Xu H, Gao Y. Aldehyde dehydrogenase, liver disease and cancer. Int J Biol Sci 2020;16:921-934. doi:10.7150/ijbs.42300.

[21] Zhang LQ, Song X, Zhao XK, Huang J, Zhang P, Wang LW, et al. Association of genotypes of rs671 withinALDH2 with risk for gastric cardia adenocarcinoma in the Chinese Han population in high- and low-incidence areas. Cancer Biol Med 2017;14:60-65. doi:10.20892/j.issn.2095-3941.2016.0089.

[22] Xia JQ, Song J, Zhang Y, An NN, Ding L, Zhang Z. Effect of aldehyde dehydrogenase 2 gene polymorphism on hemodynamics after nitroglycerin intervention in Northern Chinese Han population. Chin Med J (Engl) 2015;128:180-185. doi:10.4103/0366-6999.149192.

[23] Cho HI, Choi JW, Lee SM. Impairment of autophagosome-lysosome fusion contributes to chronic ethanol-induced liver injury. Alcohol 2014;48:717725. doi:10.1016/j.alcohol.2014.08.006.

[24] Xiao J, Wang F, Wong NK, He J, Zhang R, Sun R, et al. Global liver disease burdens and research trends: Analysis from a Chinese perspective. J Hepatol $2019 ; 71: 212-221$. doi: $10.1016 / j$.jhep.2019.03.004

[25] Wang WJ, Xiao P, Xu HQ, Niu JQ, Gao YH. Growing burden of alcoholic liver disease in China: A review. World J Gastroenterol 2019;25:1445-1456. doi:10.3748/wjg.v25.i12.1445.

[26] Mokdad AH, Ballestros K, Echko M, Glenn S, Olsen HE, Mullany E, et al. The state of US health, 1990-2016: Burden of diseases, injuries, and risk factors among US states. JAMA 2018;319:1444-1472. doi:10.1001/ jama.2018.0158.

[27] Thursz M, Kamath PS, Mathurin P, Szabo G, Shah VH. Alcohol-related liver disease: Areas of consensus, unmet needs and opportunities for further study. J Hepatol 2019;70:521-530 doi:10.1016/j.jhep.2018.10.041.

[28] Méndez C, Rey M. Characterization of polymorphisms of genes ADH2, ADH3, ALDH2 and CYP2E1 and relationship to the alcoholism in a Colombian population. Colomb Med (Cali) 2015;46:176-182. doi:10.25100/ $\mathrm{cm} . \mathrm{v} 46 \mathrm{i} 4.1899$.

[29] Mansoori AA, Jain SK. ADH1B, ALDH2, GSTM1 and GSTT1 gene polymorphic frequencies among alcoholics and controls in the arcadian population of central India. Asian Pac J Cancer Prev 2018;19:725-731. doi:10.22034/ APJCP.2018.19.3.725.

[30] Ayhan Y, Gürel ŞC, Karaca Ö, Zoto T, Hayran M, Babaoğlu M, et al. Association between ADH1C and ALDH2 polymorphisms and alcoholism in a Turkish sample. Nord J Psychiatry 2015;69:233-239. doi:10.3109/080394 Turkish sample. Nord

[31] Chang B, Hao S, Zhang L, Gao M, Sun Y, Huang A, et al. Association between aldehyde dehydrogenase 2 Glu504Lys polymorphism and alcoholic liver disease. Am J Med Sci 2018;356:10-14. doi:10.1016/j.amjms.2018.03.012.

[32] Lee HC, Lee HS, Jung $\mathrm{SH}$, Yi SY, Jung HK, Yoon JH, et al. Association 
between polymorphisms of ethanol-metabolizing enzymes and susceptibility to alcoholic cirrhosis in a Korean male population. J Korean Med Sc 2001;16:745-750. doi:10.3346/jkms.2001.16.6.745

[33] He L, Deng T, Luo H. Aldehyde dehydrogenase $2(\mathrm{ALDH} 2)$ polymorphism and the risk of alcoholic liver cirrhosis among east Asians: A meta-analysis. Yonsei Med J 2016;57:879-884. doi:10.3349/ymj.2016.57.4.879.

[34] Jorgenson E, Thai KK, Hoffmann TJ, Sakoda LC, Kvale MN, Banda Y, et al. Genetic contributors to variation in alcohol consumption vary by race/ ethnicity in a large multi-ethnic genome-wide association study. Mol Psychiatry 2017;22:1359-1367. doi:10.1038/mp.2017.101.

[35] Liu J, Yang HI, Lee MH, Jen CL, Hu HH, Lu SN, et al. Alcohol drinking mediates the association between polymorphisms of ADH1B and ALDH2 and hepatitis B-related hepatocellular carcinoma. Cancer Epidemiol Biomarkers Prev 2016;25:693-699. doi:10.1158/1055-9965.EPI-15-0961.

[36] Ma X, Zheng S, Shu Y, Wang Y, Chen X. Association of the Glu504Lys polymorphism in the aldehyde dehydrogenase 2 gene with endotheliumdependent dilation disorder in Chinese Han patients with essential hypertension. Intern Med J 2016;46:608-615. doi:10.1111/imj.12983.

[37] Gao Y, Zhou Z, Ren T, Kim SJ, He Y, Seo W, et al. Alcohol inhibits T-cell glucose metabolism and hepatitis in ALDH2-deficient mice and humans: roles of acetaldehyde and glucocorticoids. Gut 2019;68:1311-1322. doi:10.1136/gutjnl-2018-316221.

[38] Guo R, Xu X, Babcock SA, Zhang Y, Ren J. Aldehyde dedydrogenase-2 plays a beneficial role in ameliorating chronic alcohol-induced hepatic steatosis and inflammation through regulation of autophagy. J Hepatol 2015;62: 647-656. doi:10.1016/j.jhep.2014.10.009.

[39] Shen Z, Ajmo JM, Rogers CQ, Liang X, Le L, Murr MM, et al. Role of SIRT1 in regulation of LPS- or two ethanol metabolites-induced TNF-alpha proin regulation of LPS- or two ethanol metabolites-induced TNF-alpha production in cultured macrophage cell lines. Am J Physiol Gastroint
Physiol 2009;296:G1047-G1053. doi:10.1152/ajpgi.00016.2009.

[40] Gao B, Tsukamoto H. Inflammation in alcoholic and nonalcoholicfatty liver disease: Friend or foe? Gastroenterology 2016;150:1704-1709. doi:10.1053/ j.gastro.2016.01.025.

[41] Ren T, Mackowiak B, Lin Y, Gao Y, Niu J, Gao B. Hepatic injury and inflammation alter ethanol metabolism and drinking behavior. Food Chem Toxicol 2020;136:111070. doi:10.1016/j.fct.2019.111070.

[42] Zhong W, Zhang W, Li Q, Xie G, Sun Q, Sun X, et al. Pharmacological activation of aldehyde dehydrogenase 2 by Alda-1 reverses alcohol-induced hepatic steatosis and cell death in mice. J Hepatol 2015;62:1375-1381. doi:10.1016/j.jhep.2014.12.022.

[43] Guillot A, Ren T, Jourdan T, Pawlosky RJ, Han E, Kim SJ, et al. Targeting liver aldehyde dehydrogenase-2 prevents heavy but not moderate alcohol drinking. Proc Natl Acad Sci U S A 2019;116:25974-25981. doi:10.1073/ pnas. 1908137116.

[44] Dollé L, Gao B. Pharmacological chaperone therapies: Can aldehyde dehydrogenase activator make us healthier? J Hepatol 2015;62:1228-1230. doi:10.1016/j.jhep.2015.02.011.

[45] Ebrahimzadeh Leylabadlo H, Ghotaslou R, Samadi Kafil H, Feizabadi MM, Moaddab SY, Farajnia S, et al. Non-alcoholic fatty liver diseases: from role of gut microbiota to microbial-based therapies. Eur J Clin Microbiol Infect Dis 2020;39:613-627. doi:10.1007/s10096-019-03746-1.

[46] Younossi Z, Tacke F, Arrese M, Chander Sharma B, Mostafa I, Bugianesi $\mathrm{E}$, et al. Global perspectives on nonalcoholic fatty liver disease and nonhep.30251.

[47] Pydyn N, Miękus K, Jura J, Kotlinowski J. New therapeutic strategies in nonalcoholic fatty liver disease: a focus on promising drugs for nonalcoholic steatohepatitis. Pharmacol Rep 2020;72:1-12. doi:10.1007/s43440019-00020-1.

[48] Younossi ZM, Koenig AB, Abdelatif D, Fazel Y, Henry L, Wymer M. Global epidemiology of nonalcoholic fatty liver disease-Meta-analytic assessment of prevalence, incidence, and outcomes. Hepatology 2016;64:73-84. doi:10.1002/hep.28431.

[49] Younossi ZM, Marchesini G, Pinto-Cortez H, Petta S. Epidemiology of nonalcoholic fatty liver disease and nonalcoholic steatohepatitis: Implications for liver transplantation. Transplantation 2019;103:22-27. doi:10.1097/ for liver transplantation.

[50] Zhou F, Zhou J, Wang W, Zhang XJ, Ji YX, Zhang P, et al. Unexpected rapid increase in the burden of NAFLD in China from 2008 to 2018: A systematic review and meta-analysis. Hepatology 2019;70:1119-1133. doi:10.1002/ hep. 30702 .

[51] Lee HW, Wong VW. Changing NAFLD epidemiology in China. Hepatology 2019;70:1095-1098. doi:10.1002/hep.30848.

[52] Hajifathalian K, Torabi Sagvand B, McCullough AJ. Effect of alcohol consumption on survival in nonalcoholic fatty liver disease: A national prospec-
tive cohort study. Hepatology 2019;70:511-521. doi:10.1002/hep.30226.

[53] Chang Y, Cho YK, Kim Y, Sung E, Ahn J, Jung HS, et al. Nonheavy drinking and worsening of noninvasive fibrosis markers in nonalcoholic fatty liver disease: A cohort study. Hepatology 2019;69:64-75. doi:10.1002/ hep. 30170 .

[54] Chen L, Lang AL, Poff GD, Ding WX, Beier JI. Vinyl chloride-induced interaction of nonalcoholic and toxicant-associated steatohepatitis: Protection by the ALDH2 activator Alda-1. Redox Biol 2019;24:101205. doi:10.1016/j. redox.2019.101205.

[55] Oniki K, Morita K, Watanabe T, Kajiwara A, Otake K, Nakagawa K, et al. The longitudinal effect of the aldehyde dehydrogenase $2 * 2$ allele on the risk for nonalcoholic fatty liver disease. Nutr Diabetes 2016;6:e210. doi:10.1038/ nutd.2016.17

[56] Murata C, Watanabe T, Furuya $H$, Sugioka $Y$, Mikurube $H$, Yokoyama A, et al. Aldehyde dehydrogenase 2 and beta3-adrenergic receptor gene polymorphisms: their association with elevated liver enzymes and metabolic syndrome. Metabolism 2003;52:1096-1101. doi:10.1016/s0026-0495 (03)00183-5.

[57] EASL recommendations on treatment of hepatitis C 2018. J Hepatol. 2018;69:461-511. doi:10.1016/j.jhep.2018.03.026.

[58] WHO. Global hepatitis report, 2017. Available from: https://www.who.int/ hepatitis/publications/global-hepatitis-report2017/en/.

[59] Sedhom D, D'Souza M, John E, Rustgi V. Viral hepatitis and acute liver failure: Still a problem. Clin Liver Dis 2018;22:289-300. doi:10.1016/j. cld.2018.01.005

[60] Proeschold-Bell RJ, Evon DM, Yao J, Niedzwiecki D, Makarushka C, Keefe $\mathrm{KA}$, et al. A Randomized Controlled Trial of an Integrated Alcohol Reduction Intervention in Patients With Hepatitis C Infection. Hepatology 2020;71: 1894-1909. doi:10.1002/hep.31058.

[61] Younossi ZM, Zheng L, Stepanova M, Venkatesan C, Mir HM. Moderate, excessive or heavy alcohol consumption: each is significantly associated with increased mortality in patients with chronic hepatitis C. Aliment Pharmacol Ther. 2013;37:703-709. doi:10.1111/apt.12265.

[62] Ganesan M, Poluektova LY, Enweluzo C, Kharbanda KK, Osna NA. Hepatitis $C$ virus-infected apoptotic hepatocytes program macrophages and hepatic stellate cells for liver inflammation and fibrosis development: role of ethanol as a second hit. Biomolecules 2018;8:113. doi:10.3390/biom80 40113

[63] Osna NA, Ganesan M, Kharbanda KK. Hepatitis C, innate immunity and alcohol: friends or foes? Biomolecules 2015;5:76-94. doi:10.3390/ biom5010076.

[64] Ganesan M, Natarajan SK, Zhang J, Mott JL, Poluektova LI, McVicker BL, et al. Role of apoptotic hepatocytes in HCV dissemination: regulation by acetaldehyde. Am J Physiol Gastrointest Liver Physiol 2016;310:G930-G940. doi:10.1152/ajpgi.00021.2016.

[65] Ganesan M, Zhang J, Bronich T, Poluektova LI, Donohue TM Jr, Tuma DJ, et al. Acetaldehyde accelerates HCV-induced impairment of innate immunity by suppressing methylation reactions in liver cells. Am J Physiol Gastrointest Liver Physiol 2015;309:G566-G577. doi:10.1152/ajpgi. 00183.2015.

[66] Cho NE, Bang BR, Gurung P, Li M, Clemens DL, Underhill TM, et al. Retinoid regulation of antiviral innate immunity in hepatocytes. Hepatology 2016;63:1783-1795. doi:10.1002/hep.28380.

[67] Narai R, Oyama T, Ogawa M, Yamaguchi T, Kinaga T, Murakami T, et al. HBV- and HCV- infected workers in the Japanese workplace. J Occup Health 2007;49:9-16. doi:10.1539/joh.49.9.

[68] Chaudhry KK, Samak G, Shukla PK, Mir H, Gangwar R, Manda B, et al. ALDH2 deficiency promotes ethanol-induced gut barrier dysfunction and fatty liver in mice. Alcohol Clin Exp Res 2015;39:1465-1475. doi:10.1111/ acer.12777.

[69] Zhu CP, Wang AQ, Zhang HH, Wan XS, Yang XB, Chen SG, et al. Research progress and prospects of markers for liver cancer stem cells. World J Gastroenterol 2015;21:12190-12196. doi:10.3748/wjg.v21.i42.12190.

[70] Bray F, Ferlay J, Soerjomataram I, Siegel RL, Torre LA, Jemal A. Global cancer statistics 2018: GLOBOCAN estimates of incidence and mortality worldwide for 36 cancers in 185 countries. CA Cancer J Clin 2018;68:394-424. doi: $10.3322 /$ caac. 21492 .

[71] Desai A, Sandhu S, Lai JP, Sandhu DS. Hepatocellular carcinoma in noncirrhotic liver: A comprehensive review. World J Hepatol 2019;11:1-18. doi:10.4254/wjh.v11.i1.1.

[72] Lee YG, Jeon TI. Modulation of the autophagy-lysosomal pathway in hepatocellular carcinoma using small molecules. Molecules 2020;25:1580. doi: $10.3390 /$ molecules25071580.

[73] Hou G, Chen L, Liu G, Li L, Yang Y, Yan HX, et al. Aldehyde dehydrogenase-2 (ALDH2) opposes hepatocellular carcinoma progression by regulating AMP-activated protein kinase signaling in mice. Hepatology $2017 ; 65$ : 1628-1644. doi: $10.1002 /$ hep.29006.

[74] Ye X, Wang X, Shang L, Zhu G, Su H, Han C, et al. Genetic variants of ALDH2-rs671 and CYP2E1-rs2031920 contributed to risk of hepatocellular carcinoma susceptibility in a Chinese population. Cancer Manag Res 2018;10:1037-1050. doi:10.2147/CMAR.S162105.

[75] Chien J, Liu J, Lee MH, Jen CL, Batrla-Utermann R, Lu SN, et al. Risk and predictors of hepatocellular carcinoma for chronic hepatitis $\mathrm{B}$ patients with newly developed cirrhosis. J Gastroenterol Hepatol 2016;31:1971-1977. doi:10.1111/jgh.13422.

[76] Seo W, Gao Y, He Y, Sun J, Xu H, Feng D, et al. ALDH2 deficiency promotes alcohol-associated liver cancer by activating oncogenic pathways via oxidized DNA-enriched extracellular vesicles. J Hepatol 2019;71:1000-1011. doi:10.1016/j.jhep.2019.06.018.

[77] Chen J, Pan W, Chen Y, Wen L, Tu J, Liu K. Relationship of ALDH2 rs671 and CYP2E1 rs2031920 with hepatocellular carcinoma susceptibility in East
Asians: a meta-analysis. World J Surg Oncol 2020;18:21. doi:10.1186/ Asians: a meta-analysis

[78] Huang PH, Hu CC, Chien CH, Chen LW, Chien RN, Lin YS, et al. The defective allele of Aldehyde Dehydrogenase 2 gene is associated with favorable postoperative prognosis in hepatocellular carcinoma. J Cancer 2019;10:5735-5743. doi:10.7150/jca.33221.

[79] Jin S, Chen J, Chen L, Histen G, Lin Z, Gross S, et al. ALDH2(E487K) mutation increases protein turnover and promotes murine hepatocarcinogenesis. Proc Natl Acad Sci U S A 2015;112:9088-9093. doi:10.1073/pnas. esis. Proc Natl
1510757112.

[80] Chandrasekaran K, Swaminathan K, Mathan Kumar S, Clemens DL, Dey A. In vitro evidence for chronic alcohol and high glucose mediated increased oxidative stress and hepatotoxicity. Alcohol Clin Exp Res 2012;36:10041012. doi:10.1111/j.1530-0277.2011.01697.x.

[81] Kołota A, Głąbska D, Oczkowski M, Gromadzka-Ostrowska J. Oxidative stress parameters in the liver of growing male rats receiving various alco- 
holic beverages. Nutrients 2020;12:158. doi:10.3390/nu12010158.

[82] Tse AP, Sze KM, Shea QT, Chiu EY, Tsang FH, Chiu DK, et al. Hepatitis transactivator protein $X$ promotes extracellular matrix modification through HIF/LOX pathway in liver cancer. Oncogenesis 2018;7:44. doi:10.1038/ s41389-018-0052-8.

[83] Cui YQ, Liu YJ, Zhang F. The suppressive effects of Britannin (Bri) on human liver cancer through inducing apoptosis and autophagy via AMPK activation regulated by ROS. Biochem Biophys Res Commun 2018;497:916-
923. doi:10.1016/j.bbrc.2017.12.144.

[84] Gao Q, Zhu H, Dong L, Shi W, Chen R, Song Z, et al. Integrated proteogenomic characterization of HBV-related hepatocellular carcinoma. Cell 2019;179:1240. doi:10.1016/j.cell.2019.10.038.

[85] Zahid KR, Yao S, Khan ARR, Raza U, Gou D. mTOR/HDAC1 crosstalk mediated suppression of ADH1A and ALDH2 links alcohol metabolism to hepatocellular carcinoma onset and progression in silico. Front Oncol 2019;9:1000. doi:10.3389/fonc.2019.01000. 